\title{
Inconsistent performance of KDM2, a culture medium for the kidney disease bacterium Renibacterium salmoninarum, due to variation in the composition of its peptone ingredient
}

\author{
T. P. T. Evelyn, L. Prosperi-Porta
}

Department of Fisheries and Oceans, Biological Sciences Branch, Pacific Biological Station, Nanaimo, British Columbia, Canada V9R 5K6

\begin{abstract}
Occasional failures of the culture medium KDM2 to support satisfactory growth of the kidney disease bacterium Renibacterium salmoninarum (Rs) have been experienced. The failures were traced to the fact that not all production lots of a commercially available peptone, an important ingredient of the medium, support good Rs growth. This held true even though the peptone lots were obtained from the same manufacturer. To ensure KDM2 tailures are avoided, only single peptone production lots, tested and shown to be satisfactory, should be used in formulating this medium.
\end{abstract}

A culture medium (KDM2), capable of supporting the growth of the fastidious kidney disease bacterium Renibacterium salmoninarum (Rs) from highly dilute inocula, has been used for over a decade (Evelyn 1977). During this period, the medium and various of its modifications (Austin et al. 1985, Daly \& Stevenson 1985) have been successfully employed in a number of studies involving Rs.

In our laboratory, we have experienced instances in which the medium has not lived up to expectations in its ability to support the growth of Rs. Because of the infrequency of these lapses, the reasons for their occurrence were not investigated. Instead, we developed a test, described elsewhere (Evelyn et al. 1981), for objectively assessing the performance of each new batch of the medium.

Recently, we experienced one of the aforementioned failures of the medium during a particularly important experiment with Rs. This failure coincided with the publication of a report (Gudmundsdottir et al. 1988) that suggested to us that other workers might also, at times, experience problems with the medium. A review of our media production records was therefore undertaken. The review revealed that medium failures sometimes occurred when a change to a new peptone lot was made. Lot changes in other of the medium's ingre- dients did not appear to result in such problems. We hypothesized, therefore, that the problem was related to the particular production lot of a commercially available peptone used in preparing the medium. The purpose of this report is (1) to outline our experiments that confirmed the correctness of this hypothesis and, (2) to alert fish health workers to the need for using only pretested and proven lots of peptone when formulating media for growing Rs.

Materials and methods. Two experiments were conducted; in each the various batches of KDM2 medium tested varied only in the peptone production lot used in their preparation. (The peptone production lots were obtained from a single commercial supplier.) In all cases, the basal medium was supplemented with newborn bovine serum $(10 \% \mathrm{w} / \mathrm{v})$ and was prepared with $0.005 \%$ (w/v) cycloheximide (Austin et al. 1985) to reduce the chance of fungal contamination.

In the first experiment, 4 different batches of KDM2, each containing a different production lot of peptone, were compared for their Rs growth-promoting properties. A primary isolate of the pathogen (Rs 8894), obtained from a chinook salmon, Oncorhynchus tshawytscha that died of typical bacterial kidney disease (BKD), was used. A primary isolate was used to reduce the possibility that adaptation to the growth medium, brought about by repeated subculture on the medium, might mask deficiencies or toxicity in any of the peptone lots under test. The isolate was typical of Rs: it was a small, Gram-positive, non-motile and nonsporeforming rod $(0.5 \times 1.0 \mu \mathrm{m})$ that grew best at $15^{\circ} \mathrm{C}$, required cysteine for growth, and reacted with anti-Rs sera. To prepare the test inoculum, 29-d-old isolate cells were harvested from a KDM2 plate and suspended in cold, sterile peptone $(0.1 \%)$-saline $(0.9 \%$ 
$\mathrm{NaCl}$ ), i.e., (P-S) to a turbidity of $1.25 \mathrm{OD}$ at $540 \mathrm{~nm}$. The suspension was then diluted in P-S to $10^{-4}$ and replicate 25 ul aliquots drop-inoculated on plates of each of the 4 batches of medium using the method of Miles \& Misra (1938). Following imbibition of the inoculum, plates were sealed in plastic bags to prevent desiccation, and incubated, inverted, for $35 \mathrm{~d}$ at $15^{\circ} \mathrm{C}$. At this stage, Rs colonies developing from each aliquot were counted (using a stereomicroscope) and then suspended in P-S containing formalin (to prevent growth) using the technique of Bell et al. (1988). The turbidity of the resultant suspensions was determined at $540 \mathrm{~nm}$ so that growth yields with each production lot of peptone could be compared.

In the second experiment, 2 additional lots of peptone (Lots 5 and 6), one of which (Lot 5) in an earier test had supported poor Rs growth, were tested for their Rs-growth promoting properties. The approach used in this experiment was the same as that of the first except that: (1) 2 Rs isolates were used for assessing the growth promoting properties of the peptones; and (2) the isolates were obtained directly from infected kidneys of 2 chinook salmon, thus ruling out any possibility that the outcome of the experiment would be affected by prior culture of the isolates on artificial media. The isolates used were typical of Rs (see earlier) and were obtained from a cultured stock of chinook salmon experiencing a severe outbreak of BKD. Homogenates of infected kidney tissue $(10 \% \mathrm{w} / \mathrm{v}$ in cold, sterile P-S) were prepared from each chinook and serially diluted in cold, sterile P-S. Replicate $25 \mu \mathrm{l}$ aliquots of the $10^{-3}$ to $10^{-6}$ dilutions from each fish were drop-inoculated on plates of each batch of medium

Table 1. Renibacterium salmoninarum. Influence of peptone production lot used in preparing the KDM2 culture medium. on growth yields of Rs after $35 \mathrm{~d}$. The culture used was a primary isolate obtained from a chinook salmon that died of bacterial kidney disease. Growth $=$ mean growth $\pm 1 \mathrm{SD}$ measured in turbidity or no. colonies. Turbidity (at OD 540 $\mathrm{nm}$ ) was due to Rs cells from colonies developing from $25 \mu \mathrm{l}$ of Rs cell suspension ( $1.25 \mathrm{OD}$ at $540 \mathrm{~nm}$ diluted $10^{-4}$ fold); each value is the mean of 5 replicates. No. colonies: number of colonies developing from $25 \mu \mathrm{l}$ of Rs cell suspension (1.25 OD at $540 \mathrm{~nm}$ diluted $10^{-4}$ fold); each value is the mean of 8 replicates. Statistucal analysis was by analysis of variance using the Bonferroni (Dunn) t-test with natural log transformed values (SAS Institute Inc. 1985). Values in a given column with different superscript letters are significantly different at $p<0.01$

\begin{tabular}{|lcr|}
\hline $\begin{array}{c}\text { Peptone } \\
\text { lot }\end{array}$ & Turbidity & Growth \\
\hline 1 & $0.300( \pm 0.080)^{\mathrm{a}}$ & $89.3( \pm 10.0)^{\mathrm{a}}$ \\
2 & $0.033( \pm 0.021)^{\mathrm{b}}$ & $105.6( \pm 7.2)^{\mathrm{b}}$ \\
3 & $0.010( \pm 0.005)^{\mathrm{b}}$ & $88.8( \pm 6.2)^{\mathrm{a}}$ \\
4 & $0.653( \pm 0.095)^{\mathrm{a}}$ & $85.5( \pm 10.0)^{\mathrm{a}}$ \\
\hline
\end{tabular}

such that a single dilution from a single fish was placed on any given plate. Plates were incubated as described above. Readings on colony counts and on growth yield were determined as previously outlined at the incubation times shown in Table 2

Results and discussion. Table 1 summarizes the results of the first experiment in which growth of Rs obtained on 4 batches of KDM2, prepared with different production lots of peptone, was compared. Judging from the growth yields on the various batches of medium, it was obvious that some batches of peptone were markedly inferior to others. Two of the peptone lots (Lots 2 and 3) yielded significantly less growth than the other 2 (Lots 1 and 4). This difference in peptone quality was not obvious when colony counts were used as the index of the medium's performance. True, one of the peptone lots (Lot 2) yielded a colony count significantly different from the counts obtained with the other 3 . However, the difference in colony counts obtained with the various peptone lots (a maximum difference of 1.2-fold) was small relative to that obtained when growth yields were measured in terms of turbidity (maximum differences of 10 to 65 -fold). These colony count differences probably reflected the difficulty in obtaining reproducible counts using small sample volumes $(25 \mu)$ ) and were not likely related to the particular peptone lot used in preparing the medium (see also the colony counts in Table 2). The important conclusion to be drawn from the data was that colony growth, measured as turbidity, rather than colony count, was the critical criterion of peptone quality. Rs cells appeared incapable of acceptable multiplication rates when inoculated onto media prepared with certain peptone lots. This conclusion was inescapable when culture plates were examined with the naked eye. Even after a lengthy incubation period of $35 \mathrm{~d}$, Rs colonies on the media prepared with the inferior peptone lots (Lots 2 and 3) would likely have been overlooked; the colonies were so small that they could only be readily visualized and counted using a microscope (magnification $=120)$.

Table 2 records the results of the second experiment in which the growth promoting abilities of 2 additional peptone production lots were compared using 2 Rs cultures obtained directly from fish that died of BKD. As before, based on growth yields (measured as turbidity), it was clear that the peptone lots differed significantly in their ability to support Rs growth. With both Rs cultures, Lot 5 yielded considerably less growth than Lot 6, a fact that held true even after an incubation period that extended to $56 \mathrm{~d}$. Again, growth of the colonies (measured as turbidity), rather than colony count, appeared to be the criterion of peptone quality. When the medium's (peptone's) performance was based on colony counts, no conclusions as to the superiority of a particular peptone lot were possible. 
Table 2. Renibacterium salmoninarum. Influence of peptone production lot used in preparing KDM2 culture medium, on growth yields of Rs. Rs cultures used were taken directly from kidney homogenates of chinook salmon that died of bacterial kidney disease. Turbidity: OD at $540 \mathrm{~nm}$ of Rs-suspended cells derived from Rs colonies developing from $25 \mu \mathrm{l}$ of kidney homogenate at a dilution of $10^{-3}$ (Turbidity I) or $10^{-5}$ (Turbidity II) incubated for 15 or $56 \mathrm{~d}$, respectively; $\mathrm{n}=4$ for each. No. colonies: Rs colonies developing from $25 \mu$ of kidney homogenate at a dilution of $10^{-5}$ after 56 d incubation; $n=8$ for each. Statistical analysis was by the t-test (Snedecor 1946, p. 77) on natural log transformed data. For each Rs culture, the values with different superscript letters are significantly different at $p<0.01$

\begin{tabular}{|ccccc|}
\hline Rs source & Peptone lot & Turbidity I & Mean growth $( \pm 1 \mathrm{SD})$ & No. colonies \\
\hline Chinook 1 & 5 & $0.012( \pm 0.001)^{\mathrm{a}}$ & $0.013( \pm 0.001)^{\mathrm{b}}$ & $17.5( \pm 7.6)^{\mathrm{d}}$ \\
& 6 & $0.638( \pm 0.064)^{\mathrm{b}}$ & $0.429( \pm 0.076)^{\mathrm{b}}$ & $36.5( \pm 0.7)^{\mathrm{b}}$ \\
Chinook 2 & 5 & $0.013( \pm 0.001)^{\mathrm{a}}$ & $0.005( \pm 0.002)^{\mathrm{a}}$ & $78.3( \pm 19.2)^{\mathrm{d}}$ \\
& 6 & $0.637( \pm 0.103)^{\mathrm{b}}$ & $0.597( \pm 0.065)^{\mathrm{b}}$ & $41.3( \pm 17.2)^{\mathrm{b}}$ \\
\hline
\end{tabular}

The peptone lots gave significantly different colony counts with each Rs culture but the results were contradictory when both cultures were considered. Once again, the colony count differences seemed attributable to difficulties in counting small-volume samples. Based on colony size, however, it was clear that one peptone lot (Lot 5) was vastly inferior to the other (Lot 6) because, even after $56 \mathrm{~d}$ incubation, colonies on the inferior peptone could still only be readily visualized and counted using a microscope.

The foregoing results strongly suggest that lapses in performance experienced with KDM2 in the past, were due to the particular peptone production lot used in preparing the medium. It appears that we can consider ourselves fortunate that the lapses in the medium's performance have been rare to date because the present results indicate that unsatisfactory performance can be expected $50 \%$ of the time ( 3 of 6 peptone lots tested proved unsatisfactory). The results underline the importance of pre-testing the medium to ensure that it supports satisfactory growth of Rs (Evelyn et al. 1981). Only in this way can one be certain that the medium has been prepared with a satisfactory peptone lot. The fact that the peptone lots are produced by the same manufacturer is no guarantee that they will perform uniformly well.

Editorial responsibility: Managing Editor

\section{LITERATURE CITED}

Austin, B., Embley, T. M., Goodfellow, M. (1985). Selective isolation of Renibacterium salmoninarum. Fedn eur microbiol. Soc. (FEMS) Lett. 17: 111-114

Bell, G. R., Traxler, G. S., Dworschak, C. (1988). Development in vitro and pathogenicity of an erythromycin-resistant strain of Renibacterium salmoninarum, the causative agent of bacterial kidney disease in salmonids. Dis. aquat. Org. 4: 19-25

Daly, J. G., Stevenson, R. M. W (1985). Charcoal agar, a new growth medium for the fish disease bacterium Renibacterium salmoninarum. Appl. envirl Microbiol. 50: 868-871

Evelyn, T P. T (1977). An improved growth medium for the kidney disease bacterium and some notes on using the medium. Bull. Off. Int. Epiz. 87: 511-513

Evelyn, T.P. T., Ketcheson, J. E., Prosperi-Porta, L. (1981) The clinical significance of immunofluorescence-based diagnoses of the bacterial kidney disease carrier Fish Pathol. 15: 293-300

Gudmundsdottir, S., Benediktsdottir, E., Helgason, S. (1988). Comparative effectiveness of three different growth-media for primary isolation of Renibacterium salmoninarum. In: Fish Health Section. American Fisheries Society Conference Handbook. International Fish Health Conference, Vancouver, B. C., Canada, p. 84

Miles, A. A., Misra, S. S. (1938). The estimation of the bactericidal power of the blood. J. Hyg. 38: 732-749

SAS Institute lnc. (1985). SAS (c) User's Guide: Statistics, Version 5.18 edn. SAS Institute Inc. Cary, North Carolina

Snedecor, G. W. (1946). Statistical methods, 4th edn. The Collegiate Press, Inc., Ames, lowa

Manuscript first received: May 23, 1989

Revised version accepted: September 22, 1989 